Western University

Scholarship@Western

Bone and Joint Institute

$9-10-2019$

\title{
Phosphonium Polyelectrolyte Complexes for the Encapsulation and Slow Release of Ionic Cargo
}

\author{
Tristan D. Harrison \\ Western University \\ Olga Yunyaeva \\ Western University \\ Aneta Borecki \\ Western University \\ Cameron C. Hopkins \\ Western University \\ John R. De Bruyn \\ Western University
}

See next page for additional authors

Follow this and additional works at: https://ir.lib.uwo.ca/boneandjointpub

Part of the Medicine and Health Sciences Commons

\section{Citation of this paper:}

Harrison, Tristan D.; Yunyaeva, Olga; Borecki, Aneta; Hopkins, Cameron C.; De Bruyn, John R.; Ragogna, Paul J.; and Gillies, Elizabeth R., "Phosphonium Polyelectrolyte Complexes for the Encapsulation and Slow Release of Ionic Cargo" (2019). Bone and Joint Institute. 511.

https://ir.lib.uwo.ca/boneandjointpub/511 


\section{Authors}

Tristan D. Harrison, Olga Yunyaeva, Aneta Borecki, Cameron C. Hopkins, John R. De Bruyn, Paul J. Ragogna, and Elizabeth R. Gillies 


\title{
Phosphonium Polyelectrolyte Complexes for the Encapsulation and
}

\section{Slow Release of Ionic Cargo}

Tristan D. Harrison, ${ }^{\dagger}$ Olga Yunyaeva, ${ }^{\dagger}$ Aneta Borecki, ${ }^{\dagger}$ Cameron C. Hopkins,,+ John R. de Bruyn, ${ }^{*}$ Paul J. Ragogna, ${ }^{* \dagger}$ and Elizabeth R. Gillies $*, \$$

†Department of Chemistry and the Centre for Advanced Materials and Biomaterials Research, The University of Western Ontario, 1151 Richmond St., London, Ontario, Canada N6A 5B7 Department of Physics and Astronomy and the Centre for Advanced Materials and Biomaterials Research, The University of Western Ontario, 1151 Richmond St., London, Ontario, Canada N6A 3K7

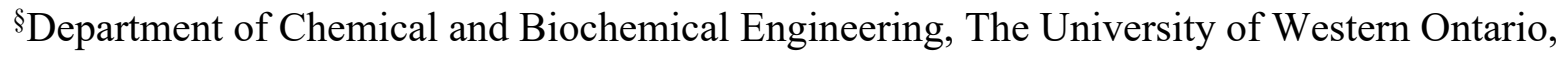
1151 Richmond St., London, Ontario, Canada N6A 5B9

\begin{abstract}
Polyelectrolyte complexation, the combination of anionically and cationically charged polymers through ionic interactions, can be used to form hydrogel networks. These networks can be used to encapsulate and release cargo, but the release of cargo is typically rapid, occurring over a period of hours to a few days and they often exhibit weak, fluid-like mechanical properties. Here we report the preparation and study of polyelectrolyte complexes (PECs) from sodium hyaluronate (HA) and poly[tris(hydroxypropyl)(4-vinylbenzyl)phosphonium chloride], poly[triphenyl(4vinylbenzyl)phosphonium chloride], poly[tri(n-butyl)(4-vinylbenzyl)phosphonium chloride] or poly[triethyl(4-vinylbenzyl)phosphonium chloride]. The networks were compacted by
\end{abstract}


ultracentrifugation, then their composition, swelling, rheological and self-healing properties were studied. Their properties depended on the structure of the phosphonium polymer and the salt concentration, but in general they exhibited predominantly gel-like behavior with relaxation times greater than $40 \mathrm{~s}$ and self-healing over $2-18 \mathrm{~h}$. Anionic molecules including fluorescein, diclofenac, and adenosine-5'-triphosphate were encapsulated into the PECs with high loading capacities of up to $16 \mathrm{wt} \%$. Fluorescein and diclofenac were slowly released over 60 days, which was attributed to a combination of hydrophobic and ionic interactions with the dense PEC network. The cytotoxicities of the polymers and their corresponding networks with $\mathrm{HA}$ to $\mathrm{C} 2 \mathrm{C} 12$ mouse myoblast cells was investigated and found to depend on the structure of the polymer and the properties of the network. Overall, this work demonstrates the utility of polyphosphonium-HA networks for the loading and slow release of ionic drugs, and that their physical and biological properties can be readily tuned according to the structure of the phosphonium polymer.

Keywords: phosphonium, ionic network, polyelectrolyte complex, drug delivery, self-healing, hyaluronic acid

\section{Introduction}

Hydrogels have been extensively explored in biomedical applications such as drug delivery ${ }^{1-3}$ and tissue engineering ${ }^{4,5}$ over the past few decades. Their high water content and soft, elastomeric properties resemble those of many soft biological tissues, allowing hydrogels to be used in vitro for the culture of cells, as well as in vivo, with minimal host response. In the field of drug delivery, hydrogels have been surgically implanted, ${ }^{6,7}$ injected, ${ }^{8}$ or applied to the skin or wounds on the surface of the body. ${ }^{9,10}$ They can provide a local release of drugs, which can be beneficial in terms of reducing side effects and reducing the frequency of dosing compared to conventional systemic 
drug administration. Cross-linking in hydrogels can be achieved through different approaches involving covalent bonding, ${ }^{11-13}$ non-covalent interactions, ${ }^{14-16}$ or a combination of both. ${ }^{17-19}$

One approach to non-covalent network formation in hydrogels is polyelectrolyte complexation. Polyelectrolytes are polymers composed of charged repeating units. Commonly used examples include the salts of poly(allylamine), ${ }^{20,21}$ poly(acrylic acid), ${ }^{22,23}$ poly(styrenesulfonate), ${ }^{24,25}$ as well as biopolymers such as hyaluronic acid ${ }^{26}$ and chitosan. ${ }^{27}$ The polymers can have a fixed charge on each repeat unit or can become charged when protonated or deprotonated by acid or base. The combination of two oppositely charged polyelectrolytes leads to polyelectrolyte complexes (PECs) held together by $\mathrm{Pol}^{-} \mathrm{Pol}^{+}$interactions between oppositely charged units on the polymers and by physical entanglements. The driving force for these interactions is the entropically favorable release of counterions ${ }^{28,29}$ and water molecules ${ }^{30}$ (Equation 1).

$$
\mathrm{Pol}^{+} \mathrm{Cl}^{-} \bullet x \mathrm{H}_{2} \mathrm{O}+\mathrm{Pol}^{-} \mathrm{Na}^{+} \bullet y \mathrm{H}_{2} \mathrm{O} \rightarrow \mathrm{Pol}^{+} \mathrm{Pol}^{-} \bullet i \mathrm{H}_{2} \mathrm{O}+\mathrm{Na}^{+}+\mathrm{Cl}^{-}+z \mathrm{H}_{2} \mathrm{O}
$$

While weak, fluid-like complexes or dense precipitates of particles often form initially through the combination of oppositely charged polyelectrolytes, it has been found in recent years that ultracentrifugation or extrusion can lead to compacted PEC networks that exhibit useful properties such as high tensile strength, elongation, and elasticity, largely dependent on hydration by water. $^{31}$ The resulting materials can exhibit self-healing behavior in the presence of salt solutions $^{31}$ and have moduli in the range of $1 \mathrm{kPa}-10 \mathrm{MPa}$, similar to many biological tissues. ${ }^{32}$ They have been explored as mimics of the nucleus pulposus of intervertebral disk, which contains negative polyelectrolyte. ${ }^{33}$ They have also been functionalized with enzymes to obtain catalytically active PECs. ${ }^{34}$ Because of the presence of numerous charged groups throughout their networks, 
compacted PECs can also potentially be used to electrostatically bind ionic drugs and release them in a controlled manner.

Polyphosphoniums have previously been used to prepare PEC thin films ${ }^{35}$ and we recently reported the preparation of PEC networks composed of poly(acrylic acid) and poly[triethyl(4vinylbenzyl)phosphonium chloride] (P-Et-P). ${ }^{36}$ The networks exhibited swelling dependent on salt concentration and dynamic, self-healing behavior at physiologically relevant salt concentrations. These properties, combined with the high capacity of the networks for ionic binding make them of interest for drug delivery applications. While it was desirable to retain the polyphosphonium component due to the possibility to easily modulate its structure and consequently network properties, drug binding, and release, we sought to replace the polyanion component with a biopolymer that would exhibit higher compatibility with biological tissues, as well as biodegradability, allowing eventual breakdown of the networks. Hyaluronic acid (HA) is a linear, anionic polysaccharide that is a natural component of the extracellular matrix. It has been used clinically in medical products for over three decades ${ }^{37}$ High molar mass HA has been shown to exhibit anti-angiogenic and anti-inflammatory properties. ${ }^{38}$ PEC hydrogels composed of HA and various polycations such as chitosan have been explored for tissue engineering ${ }^{39-41}$ and drug delivery applications. ${ }^{42-44}$ However, the release of drugs from these hydrogels, as well as other PEC hydrogels was typically rapid, occurring over a period of a few hours to days ${ }^{42-44}$ To the best of our knowledge, ionic complexes of HA with phosphonium polymers have not yet been explored.

We report here the preparation of HA PEC complexes with phosphonium polymers. The phosphonium polymer structure was varied to include ethyl, $n$-butyl, phenyl, and 3-hydroxypropyl substituents on phosphorus and the thermal properties, swelling, rheology, and self-healing properties of the different networks were studied. The effects of salt on the networks were 
evaluated. Different anionic drugs and model drugs including fluorescein, diclofenac and adenosine-5'-triphosphate were loaded into the networks, leading to high drug content ranging from $5-16 \mathrm{wt} \%$. Drug release rates depended on the structure of the drug and the PEC network, but it was possible to achieve sustained release over months, which is much longer than previously reported PECs that have been studied for drug delivery. We also evaluated the cytotoxicities of the networks and the polymers used to prepare them.

\section{Experimental}

General materials. Tri(n-butyl)(4-vinylbenzyl)phosphonium chloride (Bu-P), triethyl(4vinylbenzyl)phosphonium chloride (Et-P), triphenyl(4-vinylbenzyl)phosphonium chloride (Ph-P) and tris(hydroxypropyl)(4-vinylbenzyl)phosphonium chloride (Hp-P) were synthesized as previously reported..$^{45-47}$ Deionized (DI) water was obtained from a Barnstead Easypure II system and had a resistivity of $15 \mathrm{M} \Omega \bullet \mathrm{cm}$ or greater. Hyaluronic acid sodium salt (HA) (1000-2000 or 30-50 kg/mol) was purchased form CarboSynth (Berkshire, United Kingdom) and used as received. Phosphines were donated by Solvay (Niagara Falls, ON, Canada) and used as received. $\mathrm{D}_{2} \mathrm{O}$, 4-vinylbenzyl chloride, fluorescein sodium salt, paracetamol and all cell culture reagents were purchased from Sigma-Aldrich and used as received. Diclofenac sodium salt and adenosine5'-triphosphate disodium salt hydrate (ATP) were purchased from Alfa Aesar and used as received. Phosphate buffered saline contained $137 \mathrm{mM} \mathrm{NaCl}, 2.7 \mathrm{mM} \mathrm{KCl}, 10 \mathrm{mM} \mathrm{Na} 2 \mathrm{HPO}_{4}$, and $1.8 \mathrm{mM} \mathrm{KH}_{2} \mathrm{PO}_{4}$ with a pH of 7.4.

General methods. Differential scanning calorimetry (DSC) was performed on a DSC Q20 from TA Instruments (New Castle, DE) at a ramp rate of $10{ }^{\circ} \mathrm{C} /$ min under a $\mathrm{N}_{2}$ atmosphere in an aluminum $T_{\text {zero }}$ pan containing 5-10 $\mathrm{mg}$ of sample. Glass transition temperatures $\left(T_{g}\right)$ were obtained from the second heating cycle. Thermogravimetric analysis (TGA) to determine the onset 
degradation temperatures $\left(T_{o}\right)$ was performed on a Q600 SDT from TA Instruments and analyzed at a ramp rate of $10^{\circ} \mathrm{C} / \mathrm{min}$ up to $800^{\circ} \mathrm{C}$ using a ceramic pan containing 5-10 $\mathrm{mg}$ of dry sample. Nuclear Magnetic Resonance (NMR) spectroscopy was conducted on a Bruker AvIII HD $400 \mathrm{MHz}$ Spectrometer from $\left({ }^{1} \mathrm{H} 400.08 \mathrm{MHz},{ }^{31} \mathrm{P}\left\{{ }^{1} \mathrm{H}\right\} 161.82 \mathrm{MHz}\right)$. The chemical shifts $\left(\delta\right.$, ppm) in all ${ }^{1} \mathrm{H}$ NMR spectra were referenced relative to the residual DOH peak $\left({ }^{1} \mathrm{H} \delta=4.79\right)$. All ${ }^{31} \mathrm{P}\left\{{ }^{1} \mathrm{H}\right\}$ NMR spectra were referenced using an external standard $\left(85 \% \quad \mathrm{H}_{3} \mathrm{PO}_{4}:{ }^{31} \mathrm{P} \delta=0\right)$. UV-visible spectroscopy was conducted on a Tecan Infinite M1000 Pro plate reader. Costar 96 well UV plates (\#3635) with UV transparent flat bottoms were used. Scanning electron microscopy (SEM) was performed in the University of Western Ontario's Nanofabrication Facility using a Zeiss LEO 1530 instrument, operating at $3.0 \mathrm{kV}$ and a working distance of 4-7 mm. Samples were prepared by soaking them in DI water or PBS for $24 \mathrm{~h}$, freezing them, then lyophilizing. Samples soaked in PBS were soaked in DI water for 1 min prior to lyophilization to remove surface salt that would interfere with imaging. Samples were mounted to stubs covered in carbon tape and coated in osmium using a SPI Supplies, OC-60A plasma coater. Energy dispersive X-ray spectroscopy (EDX) was performed using a Hitachi S-3400N variable pressure microscope with a turbomolecular pump. Samples were analyzed at an accelerating voltage of $20 \mathrm{kV}$ and analyzed by EDX analysis using an INCA EDAX system and software. Samples were coated with $5 \mathrm{~nm}$ of osmium prior to analysis.

Molar mass determination. Size exclusion chromatography (SEC) of the polymers was performed using a Malvern Viscotek GPCmax instrument equipped with a Viscotek VE 3580 RI detector and two Inert series columns (P101609 and Q10183) at a constant temperature of $50{ }^{\circ} \mathrm{C}$. The eluent was $0.4 \mathrm{M}$ tetrabutylammonium triflate in $N, N$-dimethylformamide (DMF) with a flow rate of $1 \mathrm{~mL} / \mathrm{min}$. Calibration was performed using poly(methyl methacrylate) (PMMA) standards 
to determine the number average molar mass $\left(M_{n}\right)$, weight average molar mass $\left(M_{w}\right)$, and dispersity $(\bigoplus)$. The $M_{w}$ values for P-Hp-P and P-Et-P were measured by light scattering (LS) using a Malvern Zetasizer Nano-ZS instrument as previously reported..$^{48}$ The differential refractive index increment $(\mathrm{d} n / \mathrm{d} c)$ for P-Et-P has been reported previously. ${ }^{49}$ The differential refractive index increment $(\mathrm{d} n / \mathrm{d} c)$ of P-Hp-P has not been reported so $\mathrm{d} n / \mathrm{d} c$ of P-Et-P was assumed to be similar and used for both. Time averaged scattered light intensities were measured for each polymer at a series of concentrations from 0.1 to $1.0 \mathrm{mg} / \mathrm{mL}$ in $54 / 23 / 23(\mathrm{v} / \mathrm{v} / \mathrm{v})$ water/methanol/acetic acid containing 0.1 M sodium acetate. This ternary mixture was used as it prevented aggregation of polymers. ${ }^{49}$ Toluene was used as a standard for the measurements. Using these data, the $M_{w}$ for each polymer was determined from the Rayleigh equation, $K C / R_{\theta}=\left(1 / M_{w}+2 A_{2} C\right) P(\theta)$, using a Debye plot: $K C / R_{\theta}$ is plotted as a function of $C$, allowing $1 / M_{w}$ to be determined as the y-intercept. Here $C$ is the polymer concentration; $R_{\theta}$ is the excess Rayleigh ratio - the ratio of scattered to incident light intensity; $A_{2}$ is the second viral coefficient, which is a measure of solute-solvent interactions; $P(\theta)$ is a scattering function which relates the angular variation in scattering intensity to the mean square radius of the particle; $K=4 \pi^{2} / \lambda_{\mathrm{o}}{ }^{4} \mathrm{~N}_{\mathrm{A}}\left[\mathrm{n}_{\mathrm{o}}(\mathrm{d} n / \mathrm{d} c)\right]^{2}$, where $\lambda_{\mathrm{o}}$ is the vacuum wavelength of incident light; $\mathrm{N}_{\mathrm{A}}$ is Avogadro's number; and $\mathrm{n}_{\mathrm{o}}$ is the refractive index of the solvent.

\section{Synthesis of poly[tris(hydroxypropyl)(4-vinylbenzyl)phosphonium chloride] (P-Hp-P). Hp-}

P (16.7 g, $46.3 \mathrm{mmol}), 2$,2'-azobis[2-(2-imidazolin-2-yl)propane]dihydrochloride (VA-044) (75

$\mathrm{mg}, 0.23 \mathrm{mmol})$ and DI water $(210 \mathrm{~mL})$ were combined in a round bottom flask with a stir bar, and the flask was sealed with Teflon tape. $\mathrm{N}_{2}$ was bubbled through the solution using a needle with stirring at room temperature for $30 \mathrm{~min}$ to degas the reaction mixture. The reaction mixture was then heated at $60{ }^{\circ} \mathrm{C}$ for $16 \mathrm{~h}$. The solvent was then removed in vacuo. No further purification was 
necessary as no monomer peaks were visible in the resulting ${ }^{1} \mathrm{H}$ NMR spectrum. Yield $=15.9 \mathrm{~g}$, $95 \% .{ }^{1} \mathrm{H}$ NMR $\left(400 \mathrm{MHz}, \mathrm{D}_{2} \mathrm{O}\right) \delta: 1.55$ (broad s, $9 \mathrm{H}, \mathrm{P}-\mathrm{CH}_{2}-\mathrm{C}_{2}-\mathrm{CH}_{2}-\mathrm{OH}$ and backbone $\mathrm{C} \underline{\mathrm{H}}$ and $\mathrm{C}_{2}$ ), 2.09 (broad s, $\left.6 \mathrm{H}, \mathrm{P}-\mathrm{C}_{\underline{2}}-\left(\mathrm{CH}_{2}\right)_{2}-\mathrm{OH}\right), 3.48$ (broad s, $8 \mathrm{H}, \mathrm{P}-\left(\mathrm{CH}_{2}\right)_{2}-\mathrm{C}_{2}-\mathrm{OH}, \mathrm{Ar}-\mathrm{C}_{2}-$ P-( $\left.\left(\mathrm{CH}_{2}\right)_{3}-\mathrm{OH}\right), 6.49$ (broad s, $\left.2 \mathrm{H}, \mathrm{Ar}-\underline{\mathrm{H}}\right), 7.06$ (broad s, $\left.2 \mathrm{H}, \mathrm{Ar}-\underline{\mathrm{H}}\right)$ ppm. ${ }^{31} \mathrm{P}\left\{{ }^{1} \mathrm{H}\right\} \mathrm{NMR}(162$ $\left.\mathrm{MHz}, \mathrm{D}_{2} \mathrm{O}\right) \delta: 34.2 ; T_{\mathrm{g}}=115^{\circ} \mathrm{C}, T_{\mathrm{o}}=290^{\circ} \mathrm{C} ; \mathrm{LS}: M_{w}=666 \mathrm{~kg} / \mathrm{mol}$.

Synthesis of poly[triphenyl(4-vinylbenzyl)phosphonium chloride] (P-Ph-P). The synthesis was carried out as described above for P-Hp-P except that the following compounds and quantities were used: Ph-P (17.8 g $43.0 \mathrm{mmol})$; VA-044 (70 mg, $0.22 \mathrm{mmol})$; DI water (220 mL). Yield = $16.4 \mathrm{~g}, 92 \% .{ }^{1} \mathrm{H}$ NMR (400 MHz, $\left.\mathrm{D}_{2} \mathrm{O}\right) \delta: 0.99$ (broad, $\mathrm{C}_{2}$ and $\left.\mathrm{C} \underline{\mathrm{H}}\right), 4.33$ (broad, Ar-C $\underline{\mathrm{H}}_{2}-\mathrm{P}-$ $\left.\mathrm{C}_{5} \mathrm{H}_{5}\right) 5.91$ (broad, Ar- $\underline{\mathrm{H}}$ ), 6.45 (broad, Ar- $\underline{\mathrm{H}}$ ), 7.30 (broad, Ar- $\underline{\mathrm{H}}$ ) 7.60 ((broad, Ar- $\underline{\mathrm{H}}$ ) ppm. ${ }^{31} \mathrm{P}\left\{{ }^{1} \mathrm{H}\right\} \mathrm{NMR}\left(162 \mathrm{MHz}, \mathrm{D}_{2} \mathrm{O}\right) \delta: 22.15 \mathrm{ppm} ; T_{\mathrm{g}}=270{ }^{\circ} \mathrm{C}, T_{\mathrm{o}}=314{ }^{\circ} \mathrm{C} ; M_{n}=60 \mathrm{~kg} / \mathrm{mol}, M_{w}=$ $138 \mathrm{~kg} / \mathrm{mol}, \oplus=2.2$.

Synthesis of poly[tri(n-butyl)(4-vinylbenzyl)phosphonium chloride] (P-Bu-P). The synthesis was carried out as described above for P-Hp-P except that the following compounds and quantities were used: Bu-P (9.6 g, $27.1 \mathrm{mmol})$; VA-044 (44 mg, $0.14 \mathrm{mmol})$; DI water (120 mL). Yield = $8.8 \mathrm{~g}, 92 \% .{ }^{1} \mathrm{H}$ NMR $\left(400 \mathrm{MHz}, \mathrm{D}_{2} \mathrm{O}\right) \delta: 0.76$ (broad s, $10 \mathrm{H}, \mathrm{P}-\left(\mathrm{CH}_{2}\right)_{3}-\mathrm{C}_{\underline{3}}$ and backbone $\left.\mathrm{C} \underline{\mathrm{H}}\right)$, 1.29 (broad s, $14 \mathrm{H}, \mathrm{P}-\mathrm{CH}_{2}-\left(\mathrm{CH}_{2}\right)_{2}-\mathrm{CH}_{3}$ and backbone $\left.\mathrm{CH}_{2}\right), 2.05$ (broad s, $6 \mathrm{H}, \mathrm{P}-\mathrm{CH}_{2}-\left(\mathrm{CH}_{2}\right)_{2}-$ $\mathrm{CH}_{3}$ ), 3.69 (broad s, 2H Ar- $\left.\underline{\mathrm{H}}_{2}-\mathrm{P}-\left(\mathrm{CH}_{2}\right)_{3}-\mathrm{CH}_{3}\right), 6.42$ (broad s, $\left.2 \mathrm{H}, \mathrm{Ar}-\underline{\mathrm{H}}\right), 7.14$ (broad s, $2 \mathrm{H}, \mathrm{Ar}-$ H). ${ }^{31} \mathrm{P}\{1 \mathrm{H}\}$ NMR $\left(162 \mathrm{MHz}, \mathrm{D}_{2} \mathrm{O}\right) \delta: 31.71,35.75 \mathrm{ppm} ; T_{\mathrm{g}}=180{ }^{\circ} \mathrm{C}, T_{\mathrm{o}}=344{ }^{\circ} \mathrm{C} ;$ SEC: $M_{n}=$ $170 \mathrm{~kg} / \mathrm{mol}, M_{w}=450 \mathrm{~kg} / \mathrm{mol}, \bigoplus=2.6$.

Synthesis of poly[triethyl(4-vinylbenzyl)phosphonium chloride] (P-Et-P). The synthesis was carried out as described above for P-Hp-P except that the following compounds and quantities were used: Et-P (10.1 g, $37.4 \mathrm{mmol})$; VA-044 (60 mg, $0.19 \mathrm{mmol})$; DI water $(130 \mathrm{~mL})$. Yield = 
$9.3 \mathrm{~g}, 92 \% .{ }^{1} \mathrm{H}$ NMR (400 MHz, $\left.\mathrm{D}_{2} \mathrm{O}\right) \delta: 0.93$ (broad s, $10 \mathrm{H}, \mathrm{P}_{-} \mathrm{CH}_{2}-\mathrm{C}_{3} \underline{3}$ and backbone $\left.\mathrm{C} \underline{\mathrm{H}}\right), 1.45$

(broad s, 2 H, backbone $\underline{\mathrm{C}}_{2}$ ), 2.02 (broad s, $\left.6 \mathrm{H}, \mathrm{P}-\mathrm{C}_{2} \underline{2}_{-} \mathrm{CH}_{3}\right), 3.61$ (broad s, $2 \mathrm{H}, \mathrm{Ar}-\mathrm{C}_{2}-\mathrm{P}_{-}-\mathrm{CH}_{2^{-}}$ $\mathrm{CH}_{3}$ ), 6.44 (broad s, $\left.2 \mathrm{H}, \mathrm{Ar}-\underline{\mathrm{H}}\right), 7.09$ (broad s, $\left.2 \mathrm{H}, \mathrm{Ar}-\underline{\mathrm{H}}\right)$ ppm. ${ }^{31} \mathrm{P}\{1 \mathrm{H}\} \mathrm{NMR}\left(162 \mathrm{MHz}, \mathrm{D}_{2} \mathrm{O}\right)$ $\delta: 36.94 \mathrm{ppm} ; T_{\mathrm{g}}=230^{\circ} \mathrm{C}, T_{\mathrm{o}}=330{ }^{\circ} \mathrm{C} ; \mathrm{LS}: M_{w}=588 \mathrm{~kg} / \mathrm{mol}$.

Preparation of PEC networks. Phosphonium polymer and HA (1000 - $2000 \mathrm{~kg} / \mathrm{mol})$ were dissolved separately in DI water at concentrations of $0.01 \mathrm{M}$ in terms of the ions. With vigorous stirring, the solutions ( $\sim 0.8 \mathrm{~L}$ of each solution) were poured simultaneously into a large beaker and then stirred for $30 \mathrm{~min}$. The liquid was then decanted leaving polymer network. The polymer network was then packed into ultracentrifuge tubes and centrifuged for $1 \mathrm{~h}$ at $187000 \mathrm{~g}$. The networks were removed from the tubes, cut into narrow disks, and dried in vacuo until a constant weight was obtained.

\section{Measurement of swelling.}

Each network (about $150 \mathrm{mg}$, performed in triplicate) was initially dried to remove any residual water and accurately weighed to determine the dried mass $\left(m_{i}\right)$. The networks were then placed into $25 \mathrm{~mL}$ of solution at $37^{\circ} \mathrm{C}$ with $\mathrm{NaCl}$ concentrations of $0 \mathrm{M}$ (DI water), $0.1 \mathrm{M}, 0.15 \mathrm{M}, 0.25$ M or into PBS. Networks were taken out at specific time points, blotted dry with paper towel to remove surface liquid, and weighed to provide the swollen mass $\left(m_{s}\right)$. The swelling was determined using the equation:

$$
\text { Swelling } \%=\left(\frac{\mathrm{m}_{\mathrm{s}}-\mathrm{m}_{\mathrm{i}}}{\mathrm{m}_{i}}\right) \times 100
$$

Healing experiments. PECs were punctured with an 18-gauge needle, and the material was removed to create a $0.5 \mathrm{~mm}$ diameter hole. Damaged networks were imaged initially and then soaked in PBS and imaged at 2, 4, and 18 h using a Zeiss StereoLumar V12 microscope at 35x magnification. 
Anion loading. PECs (150 mg) were placed in solutions (25 mL) containing $0.05 \mathrm{wt} \%$ fluorescein sodium salt, diclofenac sodium salt, ATP or paracetamol (not anionic) for 7 days to allow time for anion exchange to occur. The PECs were then taken out of solution and quickly rinsed with deionized water to remove any unbound surface molecules. The mass of encapsulated compound was then calculated for each of the PECs by using UV-visible spectroscopy at a defined wavelength to compare the initial concentration of anion in the solution to the concentration after loading the PEC. The molar absorptivities ( $\varepsilon$, in units of $\left.\mathrm{L} \mathrm{mol}^{-1} \mathrm{~cm}^{-1}\right)$ determined from calibration curves were 13265 for fluorescein sodium salt (490 nm), 4493 for diclofenac sodium salt (276 $\mathrm{nm}), 6658$ for ATP $(260 \mathrm{~nm})$, and 4087 for paracetamol $(240 \mathrm{~nm})$. Loading content (LC) was then calculated as:

$$
\mathrm{LC}=\frac{m_{D}}{m_{N}} \times 100 \%
$$

where $m_{D}$ is the mass of anion encapsulated in the network and $m_{N}$ is the dry mass of the network. The experiments were performed in triplicate.

Anion release. Anion-loaded PECs ( $150 \mathrm{mg}$, accurately weighed) were each placed into $25 \mathrm{~mL}$ of PBS and incubated at $37^{\circ} \mathrm{C}$. Aliquots of $150 \mu \mathrm{L}$ were then taken from the solutions at specific time points and transferred into 96-well plates. The absorbances of the solutions were measured on a plate reader at the appropriate wavelength for each anion (see above) to determine the concentration and thus the quantity of drug that had been released at each time point. The PBS solutions in which the PECs were incubated were changed at each time point to maintain sink conditions. To determine the percent release, the cumulative mass of drug released at each time point was divided by the total mass of encapsulated drug in the network. The experiments were performed in triplicate. 
Rheology. PECs were prepared as described above, but after ultracentrifugation they were pressed between two Teflon sheets using a Carver 3851-0C melt press to a thickness $\sim 1 \mathrm{~mm}$. Sheets of material were then punched into thin disks with diameters of $5 \mathrm{~cm}$ then soaked in DI water or PBS at $37^{\circ} \mathrm{C}$ for $24 \mathrm{~h}$ prior to testing. Viscous and elastic moduli were measured at $37^{\circ} \mathrm{C}$ on an Anton Paar MCR 302 shear rheometer with a $5 \mathrm{~cm}$ diameter parallel plate tool (PP50). Fine grit sandpaper was affixed to the bottom plate and top plate to prevent slip when measuring the samples soaked in PBS. For samples soaked in DI water, small-amplitude oscillatory shear measurements were performed over the angular frequency range of $0.01-100 \mathrm{rad} / \mathrm{s}$ with a stress amplitude of 250 dyn $/ \mathrm{cm}^{2}$. For samples soaked in PBS, small-amplitude oscillatory shear measurements were performed over the angular frequency range of $0.01-100 \mathrm{rad} / \mathrm{s}$ with a stress amplitude of 10 $\mathrm{dyn} / \mathrm{cm}^{2}$. It was confirmed that these stress amplitudes were in the linear viscoelastic region (Figure S20). Sweeps from low to high frequency and from high to low frequency were each performed in duplicate to ensure reproducibility.

Cell toxicity assays. C2C12 mouse myoblast cells were cultured in medium consisting of $500 \mathrm{~mL}$ of Dulbecco's Modified Eagle's Medium (DMEM) supplemented with $10 \mathrm{~mL}$ of penicillinstreptomycin (1000 units $/ \mathrm{mL}), 5 \mathrm{~mL}$ of L-Glutamine $(200 \mathrm{mM})$ and $50 \mathrm{~mL}$ of fetal bovine serum, at $37^{\circ} \mathrm{C}$ in an incubator with $5 \% \mathrm{CO}_{2}$. They were then seeded in a Nunclon 96 -well $\mathrm{U}$ bottom transparent polystyrol plate to obtain approximately 10000 cells/well in $100 \mu \mathrm{L}$ of culture medium. The cells were then incubated for $24 \mathrm{~h}$ prior to performing the assay. For the leaching assays, samples of dry hydrogel $(\sim 50 \mathrm{mg})$ were immersed in $3 \mathrm{~mL}$ of culture medium and incubated overnight to enable the leaching of potentially toxic species from the hydrogels over a period of $24 \mathrm{~h}$. 
The growth medium was then aspirated from the cells and replaced with either solutions of sodium dodecyl sulfate (SDS) in the cell culture medium at concentrations of $0.2,0.15,0.10$, or $0.05 \mathrm{mg} / \mathrm{mL}$, which were used as positive controls; serial 2-fold dilutions of the leachate in culture medium; serial 2-fold dilutions of the polymers in culture medium; or fresh medium as a negative control (6 wells per concentration). The cells were then incubated at $37^{\circ} \mathrm{C}\left(5 \% \mathrm{CO}_{2}\right)$ for $24 \mathrm{~h}$. The medium was again aspirated and replaced with $110 \mu \mathrm{L}$ of fresh medium containing $0.5 \mathrm{mg} / \mathrm{mL}$ of 3-(4,5-dimethylthiazol-2-yl)-2,5- diphenyltetrazolium bromide (MTT). After $4 \mathrm{~h}$ of incubation (37 ${ }^{\circ} \mathrm{C}, 5 \% \mathrm{CO}_{2}$ ), the medium was carefully aspirated, and the purple crystals were dissolved by addition of $50 \mu \mathrm{L}$ of spectroscopic grade dimethyl sulfoxide (DMSO). After shaking (1 s, $2 \mathrm{~mm}$ amp, $654 \mathrm{rpm}$ ), the absorbance of the wells at $540 \mathrm{~nm}$ was read using a Tecan M1000-Pro plate reader. The absorbance of wells prepared in the same way but without cells was subtracted as a background and the cell viability was calculated relative to wells containing cells that were exposed only to the culture medium. No $(0 \%)$ cell viability was detected for cells exposed to the highest concentrations of SDS, confirming the sensitivity of the assay.

\section{Results and discussion}

Monomer and polymer synthesis Monomers were prepared as previously reported, by reacting tris(hydroxypropyl)phosphine, triphenylphosphine, tri(n-butyl)phosphine and triethylphosphine with 4-vinylbenzyl chloride to generate the corresponding polymerizable salts $(\mathbf{H p}-\mathbf{P}, \mathbf{P h}-\mathbf{P}, \mathbf{B u}-$ $\mathbf{P}$ and Et-P, Scheme 1). ${ }^{47,50}$ For the polymerization, conventional free radical polymerization was selected over controlled radical polymerization methods as it could more easily provide high molar mass polymers on large scale. ${ }^{36}$ The presence of long polymer chains is beneficial for chain entanglement in the PEC networks. Shorter chains will also be present due to high dispersities in chain length and they can facilitate chain mobility, which can be important for properties such as 
self-healing. ${ }^{51}$ Polymerization of the monomers to the corresponding polymers $\mathbf{P}-\mathbf{H p}-\mathbf{P}, \mathbf{P}-\mathbf{P h}-\mathbf{P}$, P-Bu-P, and P-Et-P was performed in water at $60{ }^{\circ} \mathrm{C}$ using the thermal radical initiator VA-044 for $16 \mathrm{~h}$. Complete conversion of all monomers was observed by ${ }^{1} \mathrm{H}$ and ${ }^{31} \mathrm{P}\left\{{ }^{1} \mathrm{H}\right\}$ NMR spectroscopy (Figures S1-S8).
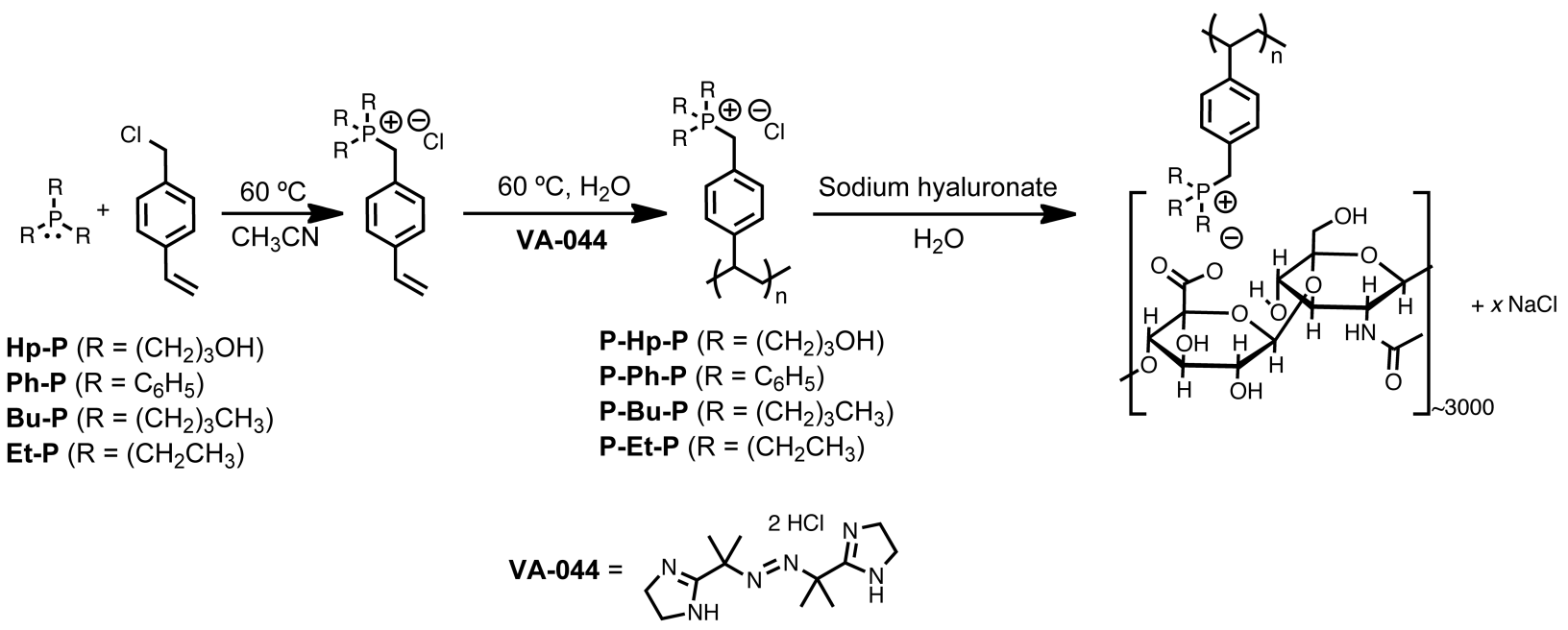

Scheme 1. Synthesis of monomers, polymers and PECs.

The molar masses of P-Ph-P $\left(M_{w}=138 \mathrm{~kg} / \mathrm{mol}, \nexists=2.2\right)$ and $\mathbf{P}-\mathbf{B u}-\mathbf{P}\left(M_{w}=450 \mathrm{~kg} / \mathrm{mol}, \nexists\right.$ = 2.6) were characterized by SEC in DMF containing $0.4 \mathrm{M}$ tetrabutylammonium triflate and equipped with inert columns designed for ionic polymers (Figure S9). However, P-Hp-P and PEt-P did not elute from this system or from an aqueous system, so they were analyzed by LS using Debye plots (Figure S10), providing $M_{w}$ values of 666 and $588 \mathrm{~kg} / \mathrm{mol}$ respectively. Onset degradation temperatures $\left(T_{o}\right)$ for the phosphonium polymers ranged from $290-344{ }^{\circ} \mathrm{C}$ (Figure S11), while that of HA was $220^{\circ} \mathrm{C}$ (Figure S12). DSC was also performed on all polymers, and the $T_{\mathrm{g}}$ values were $115,270,180,230$ and $170{ }^{\circ} \mathrm{C}$ for P-Hp-P, P-Ph-P, P-Bu-P, P-Et-P and HA respectively (Figures S13-S14). P-Ph-P has the highest $T_{\mathrm{g}}$ of $270{ }^{\circ} \mathrm{C}$, likely due to the $\pi-\pi$ stacking of the polymers. P-Et-P also had a high $T_{\mathrm{g}}$ which could be attributed to the better packing of the 
polymer chains and decreased segmental motion, compared to P-Hp-P and P-Bu-P, which have more bulky pendant groups.

Network preparation and characterization. To prepare the PEC networks, the phosphonium polymer and HA were dissolved separately in DI water, combined at 1:1 ratio of phosphonium to carboxylate, and then mixed for 30 min to allow for network formation. HA with molar masses of $30-50 \mathrm{~kg} / \mathrm{mol}$ and $1000-2000 \mathrm{~kg} / \mathrm{mol}$ were initially investigated. The networks prepared from the lower molar mass HA exhibited predominantly fluid-like behavior and could not be processed for further study (Figure S15). This was attributed to a low degree of molecular entanglement between the polymer chains. Networks prepared using $1000-2000 \mathrm{~kg} / \mathrm{mol} \mathrm{HA}$ had gel-like behavior and higher structural integrity, so they were used for all subsequent studies. The networks were then ultracentrifuged, which has been reported to transform PECs from loosely packed networks into more compact, tough, transparent solids. ${ }^{52}$ The resulting networks P-Hp-P-HA, PPh-P-HA, P-Bu-P-HA and P-Et-P-HA were then cut into pieces for characterization.

Thermal analysis was conducted on the lyophilized PEC networks. TGA indicated that each network had a multi-step degradation with a $T_{o}$ of $\sim 210^{\circ} \mathrm{C}$ corresponding to the decomposition of HA (Figure S16). The phosphonium polymers subsequently degraded at higher temperatures. DSC was also performed to examine possible phase separation. The DSC traces showed no glass transitions in the range of -10 to $200{ }^{\circ} \mathrm{C}$ (Figure S17). The absence of transitions for P-Hp-P, PBu-P and HA suggested that good mixing was obtained between these phosphonium polymers and HA. Unfortunately, higher temperatures could not be examined due to the degradation of HA, so it would not be possible to see the higher temperature glass transitions for P-Ph-P and P-Et-P. 
The dry PEC networks were also analyzed by SEM-EDX to determine the ratios of carbon and phosphorus and thus the ratio of polyphosphonium to HA in the networks. ${ }^{36}$ Atomic percentages of phosphorus relative to total carbon and phosphorus for P-Hp-P-HA, P-Ph-P-HA, P-Bu-P-HA and P-Et-P-HA were found to be $4.0 \pm 0.4,2.5 \pm 0.2,2.7 \pm 0.3$ and $2.8 \pm 0.1$ (mean \pm std dev), corresponding to carboxylate:phosphonium ratios of $(0.5 \pm 0.2): 1,(0.8 \pm 0.2): 1,(1.1 \pm 0.3): 1$ and $(1.4 \pm 0.1): 1$ respectively (calculation in the SI). Thus, the P-Hp-P-HA network contained the highest polyphosphonium content relative to the other networks. This may arise from the high $M_{w}$ and high hydrophilicity of P-Hp-P, which result in a highly extended conformation and efficient incorporation into the network. Lower incorporation of P-Et-P into the P-Et-P-HA network may be attributed to closer binding of the cation/anion pair in the phosphonium polymer, thus not allowing for efficient anion exchange with HA. It has been reported that the cation/anion pair is closer when there are less bulky substituents around phosphorus. ${ }^{49} \mathbf{P}-\mathbf{B u}-\mathbf{P}$ and $\mathbf{P}-\mathbf{P h}-\mathbf{P}$ formed networks with HA in about a 1:1 carboxylate:phosphonium ratio as expected.

PEC network swelling. PEC swelling has been implicated in the release of drugs and other molecules from PEC networks, as $\mathrm{Pol}^{-} \mathrm{Pol}^{+}$or $\mathrm{Pol}^{+} \mathrm{Drug}^{-}$interactions can be sensitive to salt concentrations. ${ }^{53-55}$ The presence of competing ions can induce increased mobility of polyions and the cleavage of ionic bonds in the network, causing swelling or network degradation. ${ }^{56}$ Therefore it was of interest to investigate the stability and swelling of the PECs in different salt solutions. Dried PECs were placed in either deionized (DI) water, $0.1,0.15,0.25 \mathrm{M} \mathrm{NaCl}$, or PBS at $37{ }^{\circ} \mathrm{C}$ and their swelling was monitored over $\sim 3$ days. The network swelling varied depending on the concentration of salt and the PEC composition (Figure 1). In each case, the swelling was highest in $0.25 \mathrm{M} \mathrm{NaCl}$. At this concentration, the structural integrity of the PECs was poor and they 
exhibited liquid-like properties. P-Hp-P-HA, P-Bu-P-HA, and P-Et-P-HA networks disintegrated and could not be further studied after about 1.5 days. The P-Ph-P-HA network remained intact at $0.25 \mathrm{M} \mathrm{NaCl}$ and swelled to the lowest degree at all salt concentrations, which can likely be attributed to increased hydrophobicity of the P-Ph-P polymer and additional interactions such as $\pi-\pi$ stacking holding the network together. ${ }^{47}$ In the solutions containing lower salt concentrations, all of the PECs maintained their structural integrity. P-Et-P-HA swelled the most, which likely results from its high hydrophilicity and lack of significant van der Waals or hydrogen bonding interactions in the network. Similar degrees of swelling were observed in PBS and $0.15 \mathrm{M} \mathrm{NaCl}$ for all of the networks, indicating that the identities of the ions do not impact swelling. In all salt solutions, the networks exhibited the "overshooting effect", which has been described as PEC swelling to a maximum value, then gradually deswelling due to chain relaxation until an equilibrium value is reached. ${ }^{43}$ PECs swelled in DI water alone had the lowest degree of swelling due to the lack of ions in solution, and no overshooting effect was observed. 

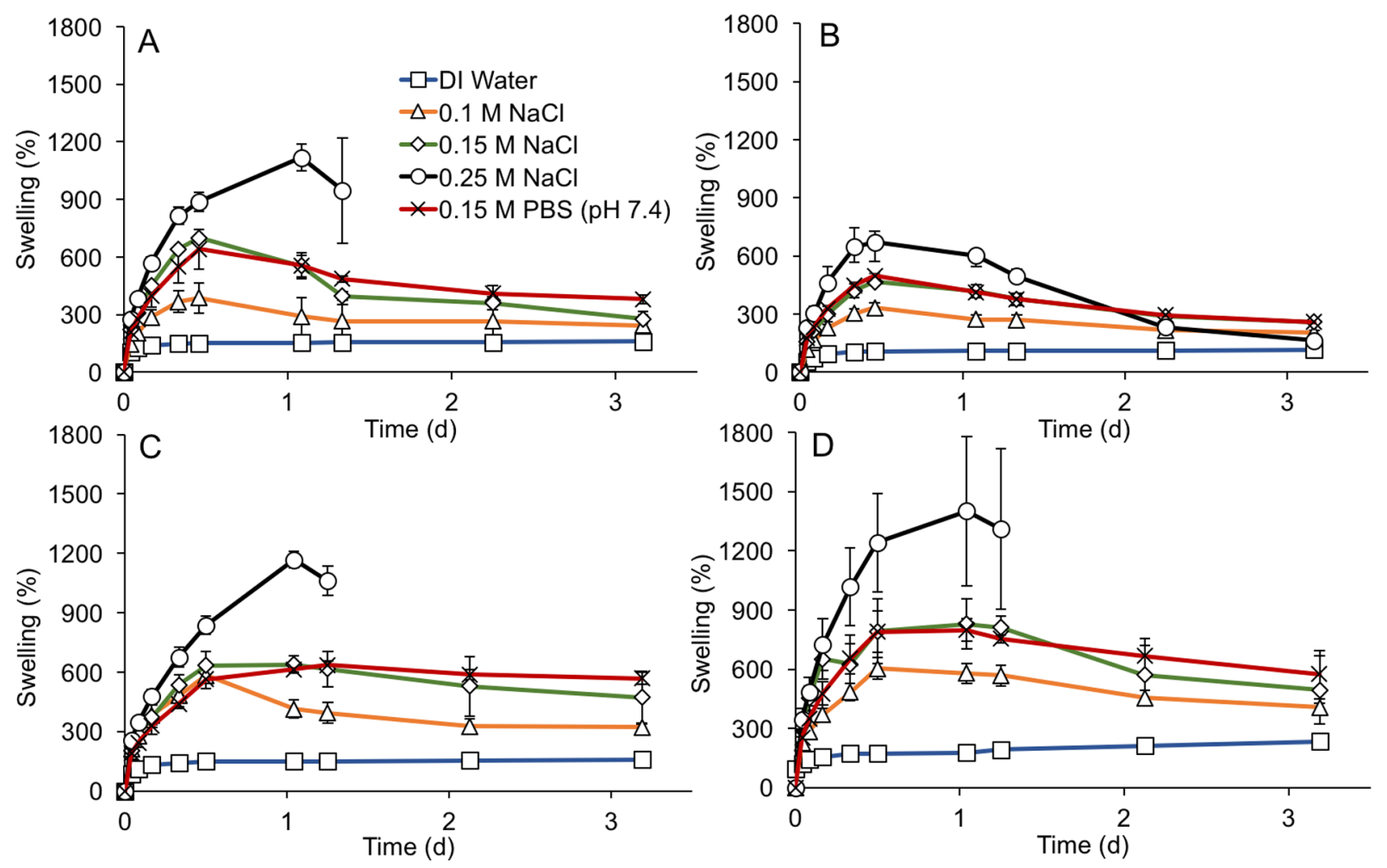

Figure 1. Swelling (wt\%) of PECs relative to the dry state: A) P-Hp-P-HA; B) P-Ph-P-HA; C) P-Bu-P-HA; and D) P-Et-P-HA. Swelling depended on the salt concentration and network composition. P-Hp-P-HA, P-Bu-P-HA, and P-Et-P-HA disintegrated at $0.25 \mathrm{M} \mathrm{NaCl}$ after $\sim 1.5$ days. Error bars correspond to standard deviations $(\mathrm{N}=3)$.

Scanning electron microscopy. The structures of the PEC networks in the dry state were examined by SEM. For PECs swelled in water, minimal porosity was observed (Figure S18), which may arise from their compact network structure in combination with artifacts of the drying process. However, the porosity of P-Ph-P-HA, P-Bu-P-HA, and P-Et-P-HA networks swelled in PBS was clear from SEM (Figure S19). The P-Et-P-HA network, which had the highest degree of swelling, also appeared to have the largest pores. P-Ph-P-HA appeared to be the least porous, consistent with its lower degree of swelling. 
Rheology. Rheology is useful to investigate the viscoelastic behavior of polymer systems.$^{57} \mathrm{It}$ can also provide information on the time scale of network relaxation. After swelling in DI water or PBS, the elastic and viscous moduli, G' and G' respectively, of the PECs were measured over an angular frequency range of 0.01 to $100 \mathrm{rad} / \mathrm{s}$ (Figure 2). When swelled in DI water, all of the PECs exhibited gel-like behavior, with G' > G" over the entire frequency range. P-Hp-P-HA, PPh-P-HA and P-Et-P-HA had elastic moduli ranging from about $10-60 \mathrm{kPa}$ and viscous moduli of 3 - $10 \mathrm{kPa}$. P-Bu-P-HA had lower elastic and viscous moduli, which can likely be attributed to the steric bulk or the hydrophobicity associated with the butyl groups limiting the extent of ionic cross-linking. G' and G" approached one another at low frequencies for each of the PECs in water. This suggests a crossover of the moduli at an angular frequency less than $0.01 \mathrm{rad} / \mathrm{s}$, corresponding to relaxation times greater than $100 \mathrm{~s}$. There did not appear to be any significant trends relating the rheological properties to the degree of swelling in DI water.

When swelled in PBS, the networks had elastic and viscous moduli that were about an order of magnitude lower than those measured in DI water. The reduction in moduli can be attributed to the added salt disrupting ionic cross-linking, enhancing polymer chain mobility, and increasing swelling. However, the networks were still predominantly elastic over a broad frequency range, suggesting that the intermolecular bonds holding the networks together were still long-lived. PHp-P-HA, P-Bu-P-HA and P-Et-P-HA had moduli crossover frequencies of 0.010, 0.025, and $0.016 \mathrm{rad} / \mathrm{s}$, corresponding to relaxation times of about 100,40 , and $63 \mathrm{~s}$ respectively. The shorter relaxation time for P-Bu-P-HA may again be attributed to weaker ionic bonding in this network. On the other hand, the moduli of P-Ph-P-HA did not crossover in the measured frequency range, suggesting longer relaxation times, due to strong bonding within this network. The longer relaxation time for P-Ph-P-HA may also result from its lower degree of swelling relative to the 
other networks; however, for the other networks no general relationship between the degree of swelling and the rheological properties was observed.
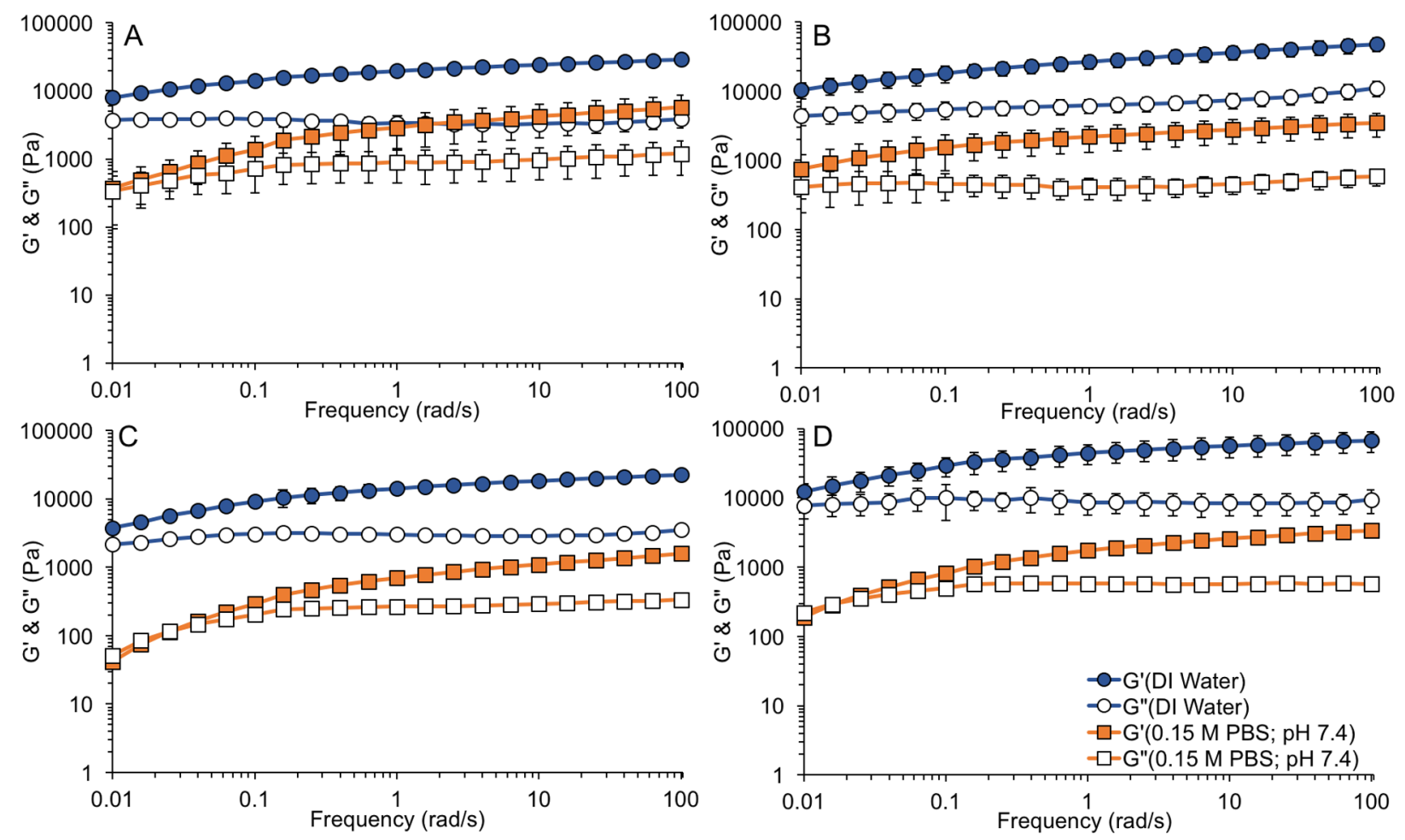

Figure 2. Rheology frequency sweeps for: A) P-Hp-P-HA; B) P-Ph-P-HA; C) P-Bu-P-HA; and D) P-Et-P-HA in DI water and PBS. Data points are means of 4 measurements at each frequency, and the error bars are standard deviations.

Self-healing. The ability of the PECs to self-heal was studied qualitatively after damaging them by boring a $\sim 0.5 \mathrm{~mm}$ hole with an 18-gauge needle, then incubating them in PBS at $37^{\circ} \mathrm{C}$ for 18 h. Despite the longer relaxation time suggested by rheology, the P-Ph-P-HA had the shortest healing time of less than 2 hours (Figure 3B). It is possible that the lower $M_{w}$ of $\mathbf{P}-\mathbf{P h}-\mathbf{P}$ compared to the other polymers contributed to faster healing by facilitating flow. In addition, as the rheology measurements were performed in the linear regime, they would not have captured low frequency, 
non-linear viscosity behavior. P-Hp-P-HA networks had the longest healing time, with damage still detected at $18 \mathrm{~h}$ (Figure 3A). This may correlate with the relatively long relaxation time of this network as indicated by rheology, its high viscous modulus, and the high $M_{w}$ of P-Hp-P. PBu-P-HA and P-Et-P-HA had fully healed by $18 \mathrm{~h}$ (Figure 3C-D). Self-healing was also investigated in DI water. All of the networks except for P-Ph-P-HA still had detectable damage after $18 \mathrm{~h}$, indicating that dynamic ion exchange facilitates healing (Figure S21). The capacities of the networks to self-heal may be of interest for delivery to tissues such as intervertebral disks or articular joints where loading may lead to deformation of the network, which could then self-heal when loading is removed, or for skin applications where they could conform to dynamic surfaces. ${ }^{58}$

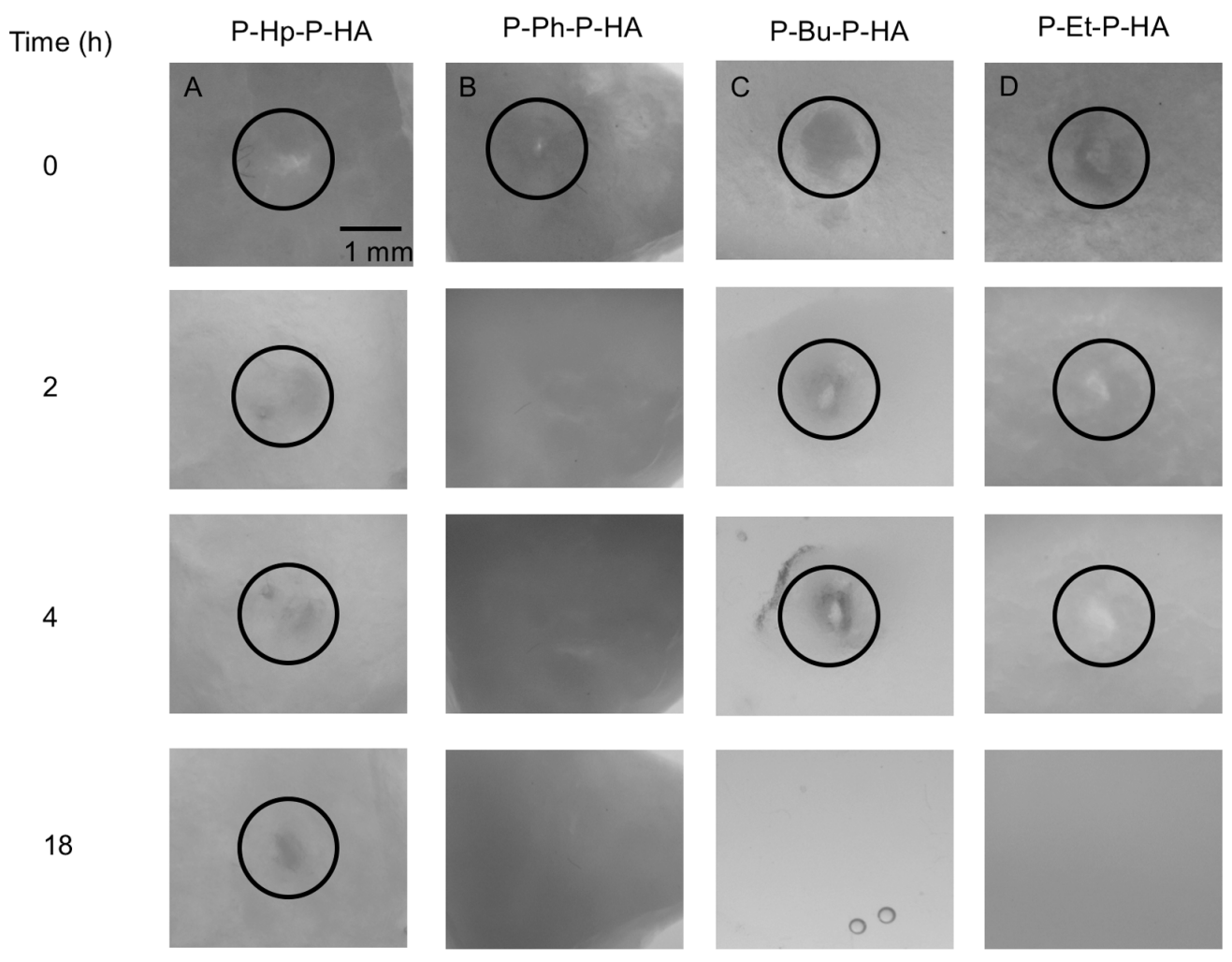

Figure 3. Digital images of PECs damaged by a $0.5 \mathrm{~mm}$ diameter hole, as indicated in the black circles, then healing over $18 \mathrm{~h}$ in PBS at $37{ }^{\circ} \mathrm{C}$ : A) P-Hp-P-HA; B) P-Ph-P-HA; C) P-Bu-P-HA; 
D) P-Et-P-HA. The black circles indicate the location of the initial damage. Bubbles were frequently observed for P-Bu-P-HA.

Loading and release studies. Due to the capacities of the PEC networks to electrostatically bind charged molecules, we investigated the loading and release of three different anionic compounds and one neutral compound (Figure 4). Loading was performed by immersion of the PECs in $\sim 0.05$ $w t \%$ solutions of the compounds in DI water. In general, high loadings were obtained for all of the anionic molecules, whereas only $\sim 1 \mathrm{wt} \%$ loading of the neutral compound paracetamol was obtained, demonstrating the importance of ionic interactions. Fluorescein was studied as it has been previously reported to bind well to accessible ammoniums and phosphoniums in polymer networks. ${ }^{46,59}$ The highest loadings of fluorescein were obtained for P-Hp-P-HA and P-Bu-P-HA (16 wt \%), followed by P-Et-P-HA (14 wt \%), and P-Ph-P-HA (9 wt\%) (Table 1). The lower loading for P-Ph-P-HA could be attributed to its lower degree of swelling compared to the other networks or to less favorable interactions with fluorescein. Diclofenac sodium salt, a nonsteroidal anti-inflammatory drug, had loadings of $11-15 \mathrm{wt} \%$, and there were no statistically significant differences between the networks ( $\mathrm{p}>0.05$ ). The loading of ATP, a dianion, was also investigated. P-Hp-P-HA afforded the highest loading of ATP (16 wt $\%)$, suggesting that hydrogen bonding to the P-Hp-P hydroxyls or the rheological properties of this network may have been important. PPh-P-HA afforded the lowest loading of $5 \mathrm{wt} \%$, most likely again due to its lower swelling, while the other two networks had intermediate loading levels. Overall, P-Hp-P-HA had a trend towards higher drug loading than the other networks, which may relate to it also having the highest phosphonium:carboxylate ratio of 2:1 and thus highest density of uncomplexed cations. However, 
the other networks did not show correlations between drug loading and the phosphonium:carboxylate ratio.

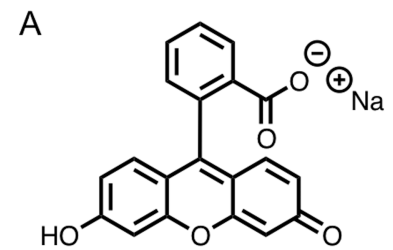

B<smiles></smiles><smiles>Nc1ncnc2c1ncn2C1OC(OP(=O)(O)OP(=O)(O)OP(=O)(O)O)C(O)C1O</smiles><smiles>CC(=O)Nc1ccc(O)cc1</smiles>

Figure 4. Anionic molecules, and a neutral control compound chosen for loading: A) fluorescein sodium salt; B) diclofenac sodium salt; C) adenosine 5'-triphosphate disodium salt; D) paracetamol

Table 1. Loading content of the PEC networks (relative to dry weight of polymer). Error bars correspond to the standard deviations $(\mathrm{N}=3)$.

\begin{tabular}{|c|c|c|c|c|}
\hline PEC & \multicolumn{3}{|c|}{ Loading content (wt \%) } \\
\hline & Fluorescein & Diclofenac & ATP & Paracetamol \\
\hline P-Hp-P-HA & $16.2 \pm 0.8$ & $10.6 \pm 0.6$ & $16.5 \pm 0.5$ & $1.2 \pm 0.2$ \\
\hline P-Ph-P-HA & $8.9 \pm 1.7$ & $12.0 \pm 2.5$ & $5.2 \pm 0.4$ & $0.8 \pm 0.8$ \\
\hline P-Bu-P-HA & $16.4 \pm 0.9$ & $15.0 \pm 1.7$ & $8.0 \pm 0.3$ & $1.3 \pm 0.4$ \\
\hline P-Et-P-HA & $13.4 \pm 0.8$ & $12.1 \pm 2.4$ & $8.9 \pm 0.3$ & $0.8 \pm 0.3$ \\
\hline
\end{tabular}

Release of each of the anionic molecules from the networks was studied in PBS at $37{ }^{\circ} \mathrm{C}$. The release of fluorescein ranged from 40 - 100\% over 60 days (Figure 5A). P-Ph-P-HA exhibited the 
highest release rate. As it also had the lowest fluorescein content, the results suggest that binding of fluorescein to this network was likely weaker than to the other networks. P-Hp-P-HA, P-BuP-HA and P-Et-P-HA exhibited more sustained release of fluorescein over 60 days, with $40-$ $60 \%$ released over this time frame. Release of diclofenac from the networks was also sustained, with $80-90 \%$ released over 60 days (Figure 5B). Similar to the results for the loading content, the release rates for diclofenac were not very dependent on the structure of the phosphonium polymer. Despite being a dianion that might exhibit stronger bivalent binding to the phosphonium polymer, ATP was rapidly released from all of the PEC networks, with $80-100 \%$ release over 1 day (Figure 5C). In addition to its different charge, ATP is also much more hydrophilic than fluorescein and diclofenac, suggesting that a combination of hydrophobic and ionic interactions may also be important for achieving slow drug release from the networks.
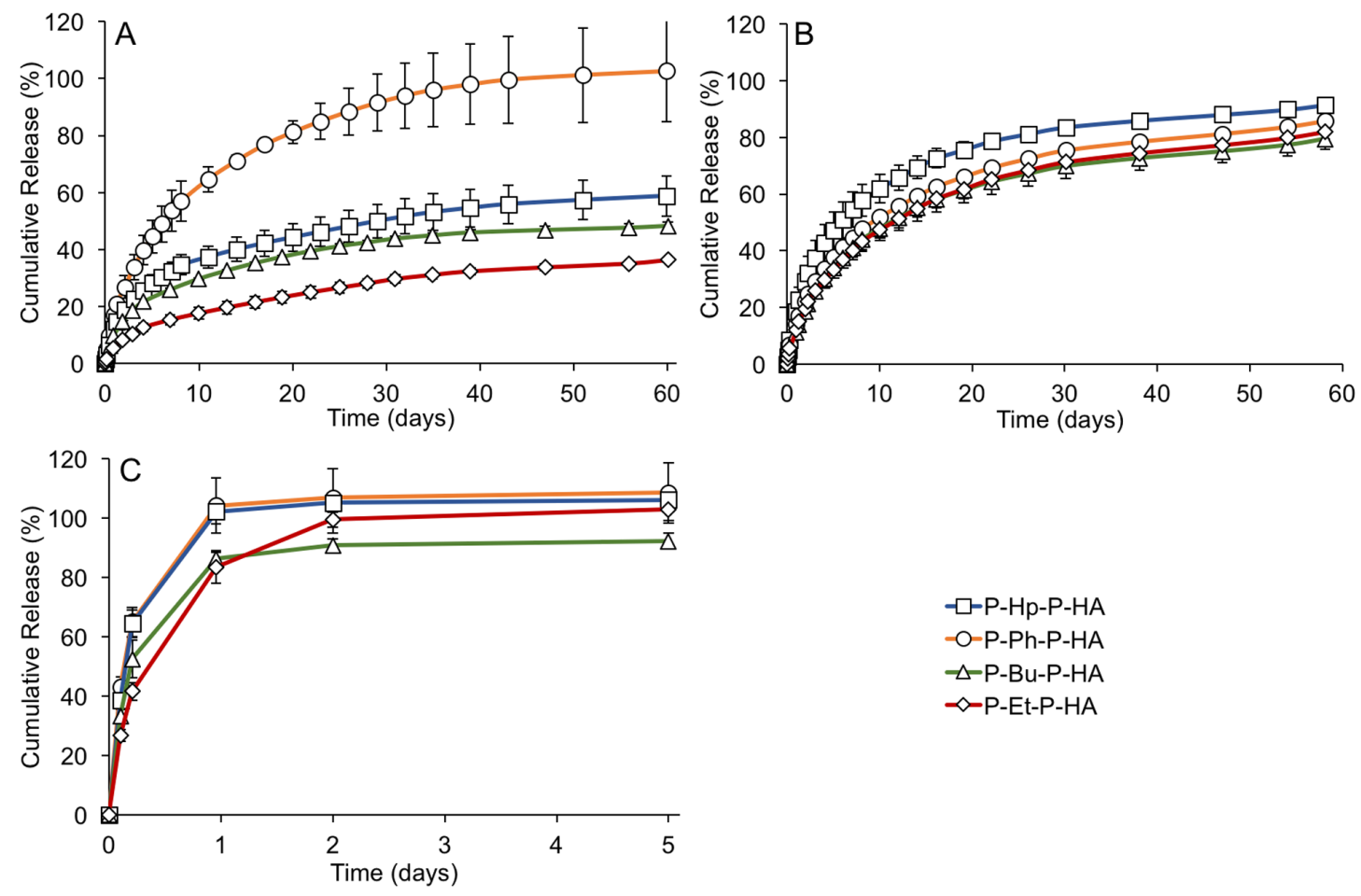

Figure 5. Release curves of A) fluorescein sodium salt, B) diclofenac sodium salt, C) ATP. Error bars correspond to the standard deviations $(\mathrm{N}=3)$. 
The anion release kinetics of fluorescein and diclofenac up to the time of $60 \%$ anion release were fit to the Korsmeyer-Peppas equation $M_{t} / M_{\infty}=k t^{n}$ where $M_{t}$ is the amount of drug released at time $t, M_{\infty}$ is the amount of drug released as time approaches infinity, $k$ is a constant, and $n$ is the diffusional exponent, which can indicate the transport mechanism (Figure S22). ${ }^{60}$ Values of $n$ ranged from $0.5-0.6$ for fluorescein, and were $\sim 0.6$ for diclofenac. Although approaching the value of 0.45 expected for pure Fickian release from disks, ${ }^{61}$ they fell in the range expected for anomalous transport, which can likely be attributed to their complex interactions with the PEC networks, as well as network swelling and possible degradation during the experiment. Overall, the slow release of fluorescein and diclofenac from our networks relative to previously reported systems can likely be attributed to the combination of ionic and hydrophobic interactions with the polymers in the network as well as the dense structure of the PECs that was achieved through ultracentrifugation.

In vitro toxicity studies. The cytotoxicities of the PECs were first probed through the potential leaching of toxic molecules from the networks. To carry out the study, PECs were incubated in cell culture medium for $24 \mathrm{~h}$, then this medium was added to cells at different dilutions. $\mathrm{C} 2 \mathrm{C} 12$ mouse myoblast cells were selected as they have been widely used for in vitro work and a MTT assay was performed to assess cell metabolic activity after incubation with the leachate for $24 \mathrm{~h}$. High cell metabolic activity ( $>80 \%$ ) was retained for P-Bu-Hp-HA, P-Ph-P-HA, and P-Et-PHA, suggesting that these networks did not leach toxic species (Figure 6). P-Bu-P-HA resulted in metabolic activities ranging from $65-83 \%$ of the control. P-Bu-P-HA was the network with the lowest G' and G', values from rheology and also had the shortest relaxation time, suggesting that 
it was more dynamic and may be the most likely to release polyphosphonium chains into the culture medium.

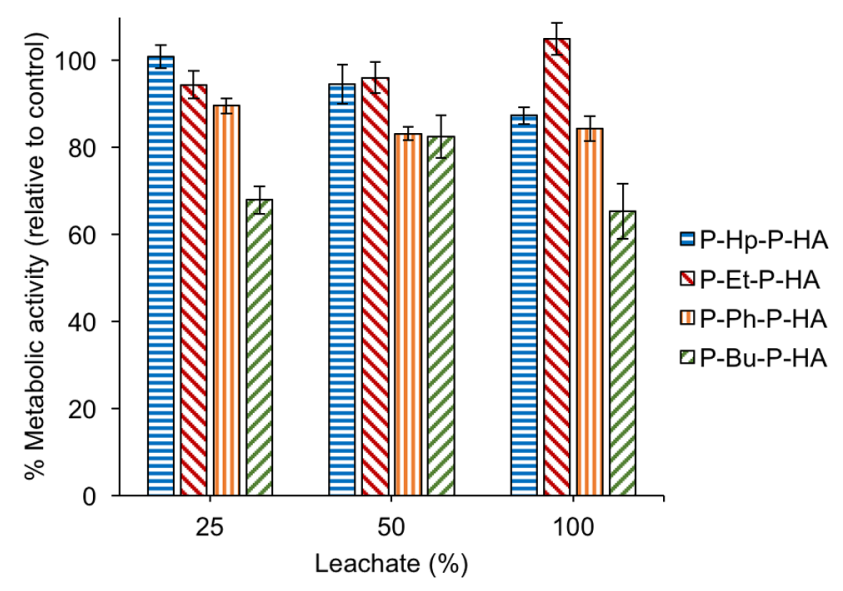

Figure 6. $\mathrm{C} 2 \mathrm{C} 12$ metabolic activities measured by MTT assays on $\mathrm{C} 2 \mathrm{C} 12$ cells incubated in culture medium that was exposed to the different PEC networks. 100\% metabolic activity corresponds to cells incubated in media that was not exposed to PEC. Error bars correspond to standard error on 6 measurements.

We also investigated the cytotoxicities of the phosphonium polymers and HA on their own using MTT assays. The metabolic activities of $\mathrm{C} 2 \mathrm{C} 12$ cells incubated in culture medium containing the polymers for $24 \mathrm{~h}$ was dependent on the polymer concentration and structure (Figure 7). As expected based on the literature, ${ }^{37}$ cells exposed to $\mathbf{H A}$ had the highest metabolic activities with $>$ $90 \%$ relative to the control up to $1 \mathrm{mg} / \mathrm{mL}$, the highest concentration evaluated. Phosphoniums, on the other hand, have been documented to act as biocides. Their mechanism of killing cells is thought to involve the disruption of cell membranes. ${ }^{62}$ Despite this, $\mathbf{P}-\mathbf{P h}-\mathbf{P}$ was found to have low cytotoxicity, with $>60 \%$ metabolic activity relative to the control at $1 \mathrm{mg} / \mathrm{mL}$, and greater than $\sim 80 \%$ metabolic activity at concentrations of $0.5 \mathrm{mg} / \mathrm{mL}$ and below. The remaining phosphonium 
polymers were more toxic, with low metabolic activities above $63 \mu \mathrm{g} / \mathrm{mL}$. The toxicity of P-Bu$\mathbf{P}$ likely explains the toxicity of P-Bu-P-HA networks observed in the leaching study. Thus, these initial biological studies suggest that P-Bu-P-HA may not be an ideal material for in vivo use. In comparing the toxicity results for the networks with those of the free polymers, P-Hp-P and P-Et$\mathbf{P}$ were much less toxic in the networks, in agreement with previous results where the toxicities of cationic ammonium polyelectrolytes were reduced upon complexation with polyanions. ${ }^{63}$ The toxicity results for P-Hp-P and P-Et-P also suggest that these polycations were not released from their corresponding networks during the leaching study. However, they should be used cautiously due to their toxicity at high concentrations. Given the low toxicity of $\mathbf{P}-\mathbf{P h}-\mathbf{P}$, it is not possible to determine based on these toxicity studies whether it leached from P-Ph-P-HA networks. However, leaching of P-Ph-P does not appear to be a major concern based on these initial experiments due to its low cytotoxicity. A more comprehensive study of the biological properties of the networks will be required in future studies.

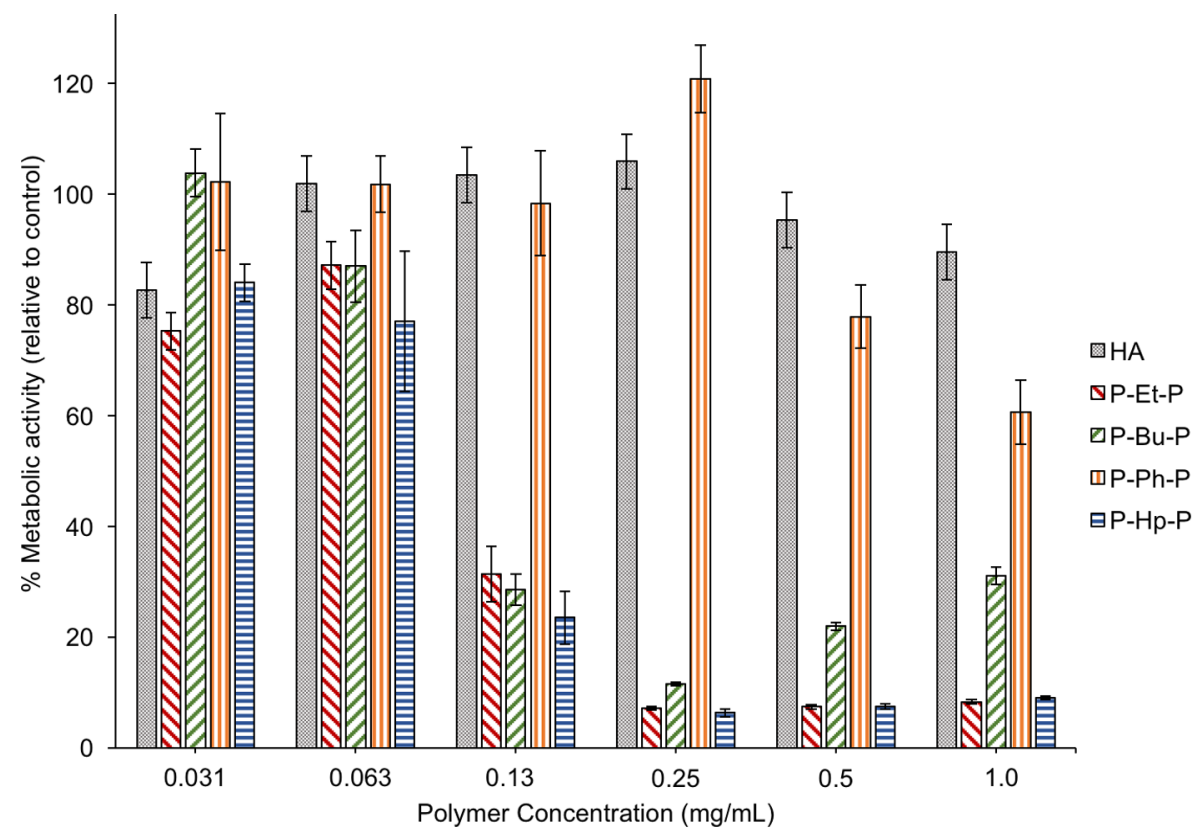


Figure 7. C2C12 metabolic activities measured by MTT assays on C2C12 cells incubated with varying concentrations of polymers dissolved in culture medium. 100\% metabolic activity corresponds to cells incubated in media that was not exposed to PEC. Error bars correspond to the standard error $(\mathrm{N}=6)$.

Conclusions. New PEC networks were prepared by mixing phosphonium polymers with HA and then using ultracentrifugation to compact the networks. The properties of the networks, such as their swelling, viscoelastic moduli, and relaxation times measured by rheology depended on the structure of the phosphonium polymer and on the presence of salts, which can both influence the strength of ionic interactions in the networks. P-Ph-P-HA afforded networks with less swelling and long relaxations times, while the P-Hp-P-HA, P-Bu-P-HA, and P-Et-P-HA networks exhibited higher swelling and shorter relaxation times. Qualitative self-healing tests showed that P-Ph-P-HA healed the fastest, P-Hp-P-HA healed more slowly, and that the presence of salt in PBS facilitated healing. Ionic molecules including fluorescein, diclofenac, and ATP could be loaded into the different networks leading to good loadings of $5-16 \mathrm{wt} \%$, while very low loading (1 wt $\%$ ) was obtained for the nonionic molecule paracetamol. Fluorescein and diclofenac were released very slowly from the networks over 60 days, which we attribute to the dense ionic network structure, combined with ionic and hydrophobic interactions. ATP, a more hydrophilic dianion, was released much more rapidly over 1-2 days. In vitro cytotoxicity studies suggested that only the P-Bu-P-HA network released toxic concentrations of polymers into cell culture media, which can be attributed to its dynamic properties that were revealed by rheology. P-Hp-P and P-Et-P were also toxic when added directly to cell culture media, but were not released from the networks at toxic concentrations over 24 h. P-Ph-P exhibited low cytotoxicity, despite the presence of cationic and hydrophobic groups on the polymer. Thus, the choice of phophonium polymer has 
important implications on the physical and biological properties of the resulting PEC network and should be selected according to the target application. In future work, it will be interesting to investigate the loading of cationic drugs, and also to explore the effect of different network compositions (e.g., anion:cation ratio) on the drug loading. Furthermore, it will also be desirable to investigate degradable phosphonium polymers.

Supporting Information. NMR spectra, SEC traces, Debye plots, TGA and DSC data, photos of the networks, calculations of network composition, SEM images, additional rheology data, Peppas model fitting of drug release kinetics. The Supporting Information is available free of charge on the ACS Publications website at DOI:

\section{Author information}

\section{Corresponding Authors}

*Email: pragogna@uwo.ca

*Email: egillie@uwo.ca

\section{Author Contributions}

The manuscript was written through contributions of all authors. All authors have given approval to the final version of the manuscript

\section{Funding Sources}

We thank the Natural Sciences and Engineering Research Council of Canada (Discovery Grants to PJR: RGPIN-2016-04457 and ERG: RGPIN-2016-04636, Collaborative Research and Development and Grant to PJR: CRDPJ 530785-18 and E. W. R. Steacie 
Memorial Fellowship to ERG: 507348-2017), an Ontario Graduate Scholarship to TDH, Solvay, and the University of Western Ontario for funding this work.

\section{Notes}

The authors declare no competing financial interest.

\section{Acknowledgements}

Matthew Coady and Ian Villamagna are thanked for help with SEM.

\section{References}

(1) Li, J.; Mooney, D. J. Designing Hydrogels for Controlled Drug Delivery. Nat. Rev. Mater. 2016, $1,1-18$.

(2) Buwalda, S. J.; Vermonden, T.; Hennink, W. E. Hydrogels for Therapeutic Delivery: Current Developments and Future Directions. Biomacromolecules 2017, 18, 316-330.

(3) Hoare, T. R.; Kohane, D. S. Hydrogels in Drug Delivery: Progress and Challenges. Polymer 2008, 49, 1993-2007.

(4) Wang, H.; Heilshorn, S. C. Adaptable Hydrogel Networks with Reversible Linkages for Tissue Engineering. Adv. Mater. 2015, 27, 3717-3736.

(5) Khademhosseini, A.; Langer, R. A Decade of Progress in Tissue Engineering. Nat. Protoc. 2016, 11, 1775-1781.

(6) Dash, A. K.; Cudworth, G. C. Therapeutic Applications of Implantable Drug Delivery Systems. J. Pharmacol. Toxicol. Methods 1998, 40, 1-12.

(7) Lee, S. C.; Kwon, I. K.; Park, K. Hydrogels for Delivery of Bioactive Agents: A 
Historical Perspective. Adv. Drug Delivery Rev. 2013, 65, 17-20.

(8) Nguyen, Q. V.; Huynh, D. P.; Park, J. H.; Lee, D. S. Injectable Polymeric Hydrogels for the Delivery of Therapeutic Agents: A Review. Eur. Polym.J. 2015, 72, 602-619.

(9) Tellechea, A.; Silva, E. A.; Min, J.; Leal, E. C.; Auster, M. E.; Pradhan-Nabzdyk, L.; Shih, W.; Mooney, D. J.; Veves, A. Alginate and DNA Gels Are Suitable Delivery Systems for Diabetic Wound Healing. Int. J. Low. Extrem. Wounds 2015, 14, 146-153.

(10) Di, J.; Yao, S.; Ye, Y.; Cui, Z.; Yu, J.; Ghosh, T. K.; Zhu, Y.; Gu, Z. Stretch-Triggered Drug Delivery from Wearable Elastomer Films Containing Therapeutic Depots. ACS Nano 2015, 9, 9407-9415.

(11) Sawhney, A. S.; Pathak, C. P.; Hubbell, J. A. Bioerodible Hydrogels Based on Photopolymerized Poly(Ethylene Glycol)-co-Poly ( $\alpha$-Hydroxy Acid) Diacrylate Macromers. Macromolecules 1993, 26, 581-587.

(12) Quick, D. J.; Anseth, K. S. DNA Delivery from Photocrosslinked PEG Hydrogels: Encapsulation Efficiency, Release Profiles, and DNA Quality. J. Controlled Release 2004, 96, 341-351.

(13) Nimmo, C. M.; Owen, S. C.; Shoichet, M. S. Diels-Alder Click Cross-Linked Hyaluronic Acid Hydrogels for Tissue Engineering. Biomacromolecules 2011, 12, 824-830.

(14) Liow, S. S.; Dou, Q.; Kai, D.; Karim, A. A.; Zhang, K.; Xu, F.; Loh, X. J. Thermogels: In Situ Gelling Biomaterial. ACS Biomater. Sci. Eng. 2016, 2, 295-316.

(15) Moore, A. N.; Hartgerink, J. D. Self-Assembling Multidomain Peptide Nanofibers for 
Delivery of Bioactive Molecules and Tissue Regeneration. Acc. Chem. Res. 2017, 50, $714-722$.

(16) Lee, K. L.; Mooney, D. J. Alginate : Properties and Biomedical Applications. Prog. Polym.Sci. 2012, 37, 106-126.

(17) Hiemstra, C.; Zhou, W.; Zhong, Z.; Wouters, M.; Feijen, J. Rapidly in Situ Forming Biodegradable Robust Hydrogels by Combining Stereocomplexation and Photopolymerization. J. Am. Chem. Soc. 2007, 129, 9918-9926.

(18) Cheng, J.; Liu, F.; Dan, S.-; Yang, Z.; Ding, C.; Zhao, L.; Qu, X.; Gu, J.; Liu, C. Dually Responsive Injectable Hydrogel Prepared by In Situ Cross-Linking of Glycol Chitosan and Benzaldehyde-Capped PEO-PPO-PEO. Biomacromolecules 2010, 11, 1043-1051.

(19) Boere, K. W. M.; Van Den Dikkenberg, J.; Gao, Y.; Visser, J.; Hennink, W. E.;

Vermonden, T. Thermogelling and Chemoselectively Cross-Linked Hydrogels with Controlled Mechanical Properties and Degradation Behavior. Biomacromolecules 2015, $16,2840-2851$.

(20) Silva, U. K. De; Weik, B. E.; Lapitsky, Y. Simple Preparation of Polyelectrolyte Complex Beads for the Long-Term Release of Small Molecules. Langmuir 2014, 30, 8915-8922.

(21) Rydzek, G.; Pakdel, A.; Witecka, A.; Noorfazidah, D.; Shri, A.; Gaudie, F.; Nicolosi, V.; Mokarian-tabari, P.; Schaaf, P.; Booulmedais, F.; Ariga, K. pH-Responsive Saloplastics Based on Weak Polyelectrolytes: From Molecular Processes to Material Scale Properties. Macromolecules 2018, 51, 4424-4434.

(22) Smith, R. J.; Long, C. T.; Grunlan, J. C. Transparent Polyelectrolyte Complex Thin Films 
with Ultralow Oxygen Transmission Rate. Langmuir 2018, 34, 11086-11091.

(23) Mikhael, J.; Schoof, S.; Andrieu-Brunsen, A.; Baier, G.; Sonja, K. Immobilization of $\alpha$ Amylase in Polyelectrolyte Complexes. J. Appl. Polym. Sci. 2017, 134, 45036.

(24) Fares, H. M.; Ghoussoub, Y. E.; Delgado, J. D.; Fu, J.; Urban, V. S.; Schleno, J. B. Scattering Neutrons along the Polyelectrolyte Complex/Coacervate Continuum. Macromolecules 2018, 51, 4945-4955.

(25) Fu, J.; Wang, Q.; Schlenoff, J. B. Extruded Superparamagnetic Saloplastic Polyelectrolyte Nanocomposites. ACS Appl. Mater. Interfaces 2015, 7, 895-901.

(26) Tang, J. D.; Caliari, S. R.; Lampe, K. J. Temperature-Dependent Complex Coacervation of Engineered Elastin-like Polypeptide and Hyaluronic Acid Polyelectrolytes.

Biomacromolecules 2018, 19, 3925-3935.

(27) Gallardo-Rivera, R.; Aguilar-Santamaría, M. D. L. Á.; Silva-Bermúdez, P.; García-López, J.; Tecante, A.; Velasquillo, C.; Román-Guerrero, A. Polyelectrolyte Complex of Aloe Vera, Chitosan, and Alginate Produced Fibroblast and Lymphocyte Viabilities and Migration. Carbohydr. Polym. 2018, 192, 84-94.

(28) Laugel, N.; Betscha, C.; Winterhalter, M.; Voegel, J. C.; Schaaf, P.; Ball, V. Relationship between the Growth Regime of Polyelectrolyte Multilayers and the Polyanion/Polycation Complexation Enthalpy. J. Phys. Chem. B 2006, 110, 19443-19449.

(29) Fu, J.; Schlenoff, J. B. Driving Forces for Oppositely Charged Polyion Association in Aqueous Solutions: Enthalpic, Entropic, but Not Electrostatic. J. Am. Chem. Soc. 2016, 138, 980-990. 
(30) Schlenoff, J. B.; Rmaile, A. H.; Bucur, C. B. Hydration Contributions to Association in Polyelectrolyte Multilayers and Complexes: Visualizing Hydrophobicity. J. Am. Chem. Soc. 2008, 130, 13589-13597.

(31) Schaaf, P.; Schlenoff, J. B. Saloplastics: Processing Compact Polyelectrolyte Complexes. Adv. Mater. 2015, 27, 2420-2432.

(32) Akhtar, R.; Sherratt, M. J.; Cruickshank, J. K.; Derby, B. Characterizing the Elastic Properties of Tissues. Mater. Today 2012, 14, 96-105.

(33) Porcel, C. H.; Schlenoff, J. B. Compact Polyelectrolyte Complexes: "Saloplastic" Candidates for Biomaterials. Biomacromolecules 2009, 10, 2968-2975.

(34) Tirado, P.; Reisch, A.; Roger, E.; Boulmedais, F.; Jierry, L.; Lavalle, P.; Voegel, J.; Schaaf, P.; Schlenoff, J. B.; Frisch, B. Catalytic Saloplastics: Alkaline Phosphatase Immobilized and Stabilized in Compacted Polyelectrolyte Complexes. Adv. Funct. Mater. 2013, 23, 4785-4792.

(35) Al-Hariri, L. A.; Reisch, A.; Schlenoff, J. B. Exploring the Heteroatom Effect on Polyelectrolyte Multilayer Assembly: The Neglected Polyoniums. Langmuir 2011, 27, 3914-3919.

(36) Cuthbert, T. J.; Jadischke, J. J.; De Bruyn, J. R.; Ragogna, P. J.; Gillies, E. R. Self-Healing Polyphosphonium Ionic Networks. Macromolecules 2017, 50, 5253-5260.

(37) Burdick, J. A.; Prestwich, G. D. Hyaluronic Acid Hydrogels for Biomedical Applications. Adv. Mater. 2011, 23, 41-56. 
(38) Stern, R.; Asari, A. A.; Sugahara, K. N. Hyaluronan Fragments: An Information-Rich System. Eur. J. Cell Biol. 2006, 85, 699-715.

(39) Costa, R. R.; Soares, D.; Reis, R. L.; Pashkuleva, I. Bioinspired Baroplastic Glycosaminoglycan Sealants for Soft Tissues. Acta Biomater. 2019, 87, 108-117.

(40) Brekke, J. H.; Scott, C. M.; Chai, Y. W.; Ulrich, C.; Sandquist, L.; Kokkoli, E.; Brien, T. D. O. A Chitosan-Hyaluronan-Based Hydrogel-Hydrocolloid Supports In Vitro Culture and Differentiation of Human Mesenchymal Stem/Stromal Cells. Tissue Eng. Part A 2015, 21, 1952-1962.

(41) Rajaram, A.; Schreyer, D. J.; Chen, D. X. B.; Rajaram, A.; Schreyer, D. J.; Chen, D. X. B. Use of the Polycation Polyethyleneimine to Improve the Physical Properties of Alginate Hyaluronic Acid Hydrogel during Fabrication of Tissue Repair Scaffolds. J. Biomater. Sci. Polym. Ed. 2015, 26, 433-445.

(42) Lai, W.; Shum, H. C. Hypromellose-Graft-Chitosan and its Polyelectrolyte Complex as Novel Systems for Sustained Drug Delivery. ACS Appl. Mater. Interfaces 2015, 7, 1050110510.

(43) Gierszewska, M.; Ostrowska-czubenko, J.; Chrzanowska, E. pH-Responsive Chitosan/ Alginate Polyelectrolyte Complex Membranes Reinforced by Tripolyphosphate. Eur. Polym. J. 2018, 101, 282-290.

(44) Chen, L.; Zheng, Y.; Feng, L.; Liu, Z.; Guo, R.; Zhang, Y. Novel Hyaluronic Acid Coated Hydrophobically Modified Chitosan Polyelectrolyte Complex for the Delivery of Doxorubicin. Int. J. Biol. Macromol. 2019, 126, 254-261. 
(45) Kanazawa, A.; Ikeda, T.; Endo, T. Novel Polycationic Biocides: Synthesis and Antibacterial Activity of Polymeric Phosphonium Salts. J. Polym. Sci., Part A: Polym. Chem. 1993, 31, 335-343.

(46) Cuthbert, T. J.; Harrison, T. D.; Ragogna, P. J.; Gillies, E. R. Synthesis, Properties, and Antibacterial Activity of Polyphosphonium Semi-Interpenetrating Networks. J. Mater. Chem. B 2016, 4, 4872-4883.

(47) Harrison, T. D.; Ragogna, P. J.; Gillies, E. R. Phosphonium Hydrogels for Controlled Release of Ionic Cargo. Chem. Commun. 2018, 11164-11167.

(48) Bonduelle, C. V.; Karamdoust, S.; Gillies, E. R. Synthesis and Assembly of Butyl RubberPoly(ethylene oxide) Graft Copolymers: From Surface Patterning to Resistance to Protein Adsorption. Macromolecules 2011, 44, 6405-6415.

(49) Hemp, S. T.; Zhang, M.; Allen, M. H.; Cheng, S.; Moore, R. B.; Long, T. E. Comparing Ammonium and Phosphonium Polymerized Ionic Liquids: Thermal Analysis, Conductivity, and Morphology. Macromol. Chem. Phys. 2013, 214, 2099-2107.

(50) Kanazawa, Akihiko; Ikeda, T. E. T. Novel Polycationic Biocides: Synthesis and Antibacterial Activity of Polymeric Phosphonium Salts. J. Polym. Sci., Part A: Polym. Chem. 1993, 31, 335-343.

(51) Tsenoglou, C. Molecular Weight Polydispersity Effects on the Viscoelasticity of Entangled Linear Polymers. Macromolecules 1991, 24, 1762-1767.

(52) Porcel, C.; Schlenoff, J. Compact Polyelectrolyte Complexes:“Saloplastic” Candidates for Biomaterials. Biomacromolecules 2009, 10, 2968-2975. 
(53) Yan, J. K.; Wang, Y. Y.; Qiu, W. Y.; Wu, J. Y. Construction and Characterization of Nanosized Curdlan Sulfate/Chitosan Polyelectrolyte Complex toward Drug Release of Zidovudine. Carbohydr. Polym. 2017, 174, 209-216.

(54) Tan, C.; Celli, B. G.; Lee, M.; Licker, J.; Abbaspourrad, A. Polyelectrolyte Complex Inclusive Biohybrid Microgels for Tailoring Delivery of Copigmented Anthocyanins. Biomacromolecules 2018, 19, 1517-1527.

(55) Lawrence, P. G.; Patil, P. S.; Leipzig, N. D.; Lapitsky, Y. Ionically Cross-Linked Polymer Networks for the Multiple-Month Release of Small Molecules. ACS Appl. Mater. Interfaces 2016, 8, 4323-4335.

Sun, J.; Liu, X.; Shen, J. In Multilayer Thin Films: Sequential Assembly of Nanocomposite Materials, Volume 1; Decher, G., Schlenoff, J. B., Eds.; Wiley-VCH Verlag GmbH \& Co. KGaA: Weinheim, Germany, 2012; p. 143.

Chen, D. T. N.; Wen, Q.; Janmey, P. A.; Crocker, J. C.; Yodh, A. G. Rheology of Soft Materials. Annu. Rev. Condens. Matter Phys. 2010, 1, 301-322.

(58) Khan, T. A.; Peh, K. K.; Seng, H. Mechanical, Bioadhesive Strength and Biological Evaluations of Chitosan Films for Wound Dressing. J. Pharm. Pharm. Sci. 2000, 3, 303311.

(59) Murata, H.; Koepsel, R. R.; Matyjaszewski, K.; Russell, A. J. Permanent, Non-Leaching Antibacterial Surface 2: How High Density Cationic Surfaces Kill Bacterial Cells. Biomaterials 2007, 28, 4870-4879.

(60) Siepmann, J.; Peppas, N. A. Higuchi Equation: Derivation, Applications, Use and Misuse. 
Int. J. Pharm. 2011, 418, 6-12.

(61) Ritger, P. L.; Peppas, N. A. A Simple Equation for Description of Solute Release I. Fickian and Non-Fickian Release from Non-Swellable Devices in the Form of Slabs, Spheres, Cylinders or Discs. J. Controlled Release 1987, 5, 23-36.

(62) Kenawy, E.-R.; Worley, S. D.; Broughton, R. The Chemistry and Applications of Antimicrobial Polymers: A State-of-the-Art Review. Biomacromolecules 2007, 8, 1359_ 1384.

(63) Martinez, J. S.; Keller, T. C. S.; Schlenoff, J. B. Cytotoxicity of Free versus Multilayered Polyelectrolytes. Biomacromolecules 2011, 12, 4063-4070. 
For Table of Contents Use Only

Phosphonium Polyelectrolyte Complexes for the Encapsulation and Slow Release of Ionic Cargo

Tristan D. Harrison, Olga Yunyaeva, Aneta Borecki, Cameron C. Hopkins, John R. de Bruyn, Paul J. Ragogna, and Elizabeth R. Gillies

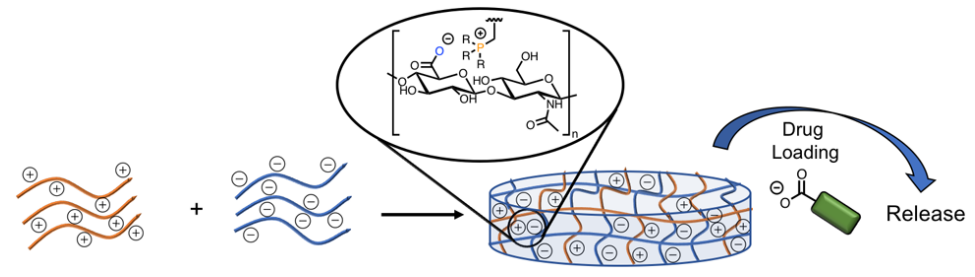

